\title{
LOOKS:
}

\section{Studio 54 and the Production of Fabulous Nightlife}

\author{
$\bullet$ Feature Article $\longrightarrow$ \\ MADISON MOORE \\ UNIVERSITY OF RICHMOND (UNITED STATES)
}

\begin{abstract}
This article combines my experience as a party-host and nightlife-creator with a close reading of Studio 54 as a theatrical production. I call for a consideration of how the staging of nightlife functions as an art form, relying on the dual practices of creation and curation. I provide a close reading of the tightly-staged Studio 54 experience, focusing on the club's infamously tight door policy and production of fabulousness to reveal what scholars and ethnographers of nightlife can learn from approaching nightlife as an artistic production. This approach can also inform a nightlife-focused research agenda.
\end{abstract}

KeYwords: Studio 54; fashion; nightlife; Andy Warhol; relational aesthetics; ethnography; velvet rope; disco; New York

madison moore is a Staff Writer at Thought Catalog and a Post-Doctoral Fellow in the Department of Theater and Dance at the University of Richmond. In December 2012 madison earned the $\mathrm{PhD}$ in American Studies from Yale University. He is the author of the Thought Catalog eBook How To Be Beyoncé and is at work on a book about fabulousness. Email madison at $<$ madison.moore@aya.yale. $\underline{\text { edu }}>$ or visit his website, $<$ http://www.madisonmooreonline.com $>$.

Dancecult: Journal of Electronic Dance Music Culture 5(1): 61-74 ISSN 1947-5403 @2013 Dancecult http://dj.dancecult.net

DOI: 10.12801/1947-5403.2013.05.01.04 


\section{INTRODUCTION}

MY NAME IS ON THE FLYER underneath hers in bold, green letters. The letters of my name are smaller than hers, but I do not feel any less significant because of it. "Party with the Party People", the flyer says, and I am given 5,000 postcard-sized invitations to leave in cool spots around New York, to hand out to people I see on the street and to take with me everywhere I go. This was the night I hosted a party with transsexual nightlife icon Amanda Lepore, and it was the night I discovered how to study nightlife. The party happened on 27 February 2012 at Santos Party House in New York City, the nightclub brainchild of legendary party monster Andrew WK. As I danced to the hot beats of the vogue-ball and house-circuit DJ Vjuan Allure in my ten-inch stilettos, black PVC pants and every piece of jewelry I could find in my apartment-far removed from critical readings on nightlife-I realized that the best approach to the study of night cultures is a deeply engaged one.

This was not the first time I have hosted or been directly involved with creating a party environment. For three years I was the creative director of an art party in New Haven, Connecticut, that took place in a downtown art gallery, and I am currently in the process of planning a new one in Richmond, Virginia. But the party I hosted with Amanda Lepore represented both the practical and theoretical culmination of my experience as a doer of nightlife. The moments leading up to the event were especially revelatory: the back-andforth email conversations about which bands should play, which DJs should spin, what people were planning on wearing, who was going to be on the guest list and what time everything should begin. In effect, this was all a process of staging nightlife not unlike the way a play is staged for the theater.

When most of us go out to our favorite bars and clubs, we do not realize the amount of detail and work that goes into making the night actually come together. We do not think about how the promoters and hosts have spent a great deal of time imagining what the party should be. This indicates to me a fundamental tool in the study of nightlife: supplementing historical and ethnographic study with a view of nightlife as a form of social sculpture. Indeed, if the question at the center of this volume is how to conduct nightlife-fieldwork, then hosting a party and understanding it as social sculpture offers an indispensible lens of critique that cannot be afforded through other means of analysis. A party is a loosely scripted work of art, and when we understand the party as an aesthetic proposition, nightlife becomes a cultural form, a unique relational space of creation and curation. I wish to explore here the value of approaching nightlife as an artistic installation, as an act of curation and creation. There is a long history, in New York especially, of "happenings" and other performance-art practices that involve staging events, such as Fluxus or relational aesthetics. I situate my own work as a party-organizer within this historical lineage.

I begin by describing what I mean by nightlife as a site of curation and creation before moving to an analysis of Studio 54 that serves as a historical case study of curated nightlife experience. In the broader scheme of nightlife history and dance music culture, historians of nightlife, cultural theorists as well as prominent DJs have long suggested that Studio 
54 symbolized everything that went wrong with disco. In her revisionist history of disco culture, Alice Echols crafts a narrative that moves away from the Saturday Night Fever, white-male heterosexualization of an underground culture that was largely black, Latino and gay. She found that Studio 54 "was reportedly meant to be a white, Hollywood version of the fashionable black Manhattan disco Leviticus" (2010: 195). In Richard Dyer's words, disco was fundamentally a black music because of the way it encouraged physicality, closeness, and rhythm:

The use of insistent black rhythms in disco music, recognizable by the closeness of the style to soul and reinforced by such characteristic features of black music as the repeated changed phrase and the use of various African percussion instruments, means that it inescapably signifies physicality (Dyer 1979: 22).

The problem with using Studio 54 as an example has less to do with the historical value or merit of the club itself and more with a lopsided and largely inaccurate depiction of Studio 54 as the culmination of disco culture, when New York disco was already flourishing underground for years in places like David Mancuso's Loft, the Sanctuary, Paradise Garage and Nicky Siano's Gallery.

"The thing is they added this other dimension", Siano once said in an interview. At Studio 54, "it was about the body; it was about the look; it was about the drugs; it was about the sex. Clubs before that, it really wasn't the raison d'etre. And it fucked the whole thing up. It was so self-centered" (Brewster and Broughton 2010: 151). But when has nightlife not been about the body, controlling where bodies can go, which bodies can be gathered in particular spaces or what is appropriate to wear at night? For Siano, in other words, Studio 54 featured the superfluous and perhaps more commercialized aspects of nightlife culture, not necessarily the vibe, the music or even the DJs. It was focused on the fleeting experience-the look, which "fucked the whole thing up". But this, in fact, is my chief interest in Studio 54: it was a culture of many and various kinds of looks-of seeing and being seen, a uniquely modern urban experience, of "working looks", of getting dressed to experience nightlife. In my view, fashion and the culture of working a look must be seen as vital elements of the nightlife sensorium. I thus concur with Fiona Buckland's analysis of queer night spaces in the 1990s, which highlights the importance of a "currency of fabulousness" for largely disenfranchised black and Latino gay men, for whom being fabulous is not so much self-centered as it is a centering of the self-a minoritized self that uses nightlife as a space to claim a sense of agency (2002: 38).

In the fall of 2011 I taught an advanced American Studies Junior Seminar at Yale University called "Dance Music and Nightlife Culture in New York City". The goal was to introduce students to the study of popular culture more broadly, and to the study of the night more specifically. Why do we party? How can studying nightlife illuminate American cultural history? Making waves from "Page Six" of the New York Post to Guest Of A Guest, New York magazine and even NPR, the course received a great deal of attention in the international media circuit, mostly due to the widely-held opinion that nightlife 
is not an appropriate topic of academic study. To the untrained eye, nightlife can appear to be exclusively dedicated to decadence and the pursuit of pleasure. It is, of course, but not exclusively. When the Post splashed the headline "Yale meets the velvet rope" across "Page Six" on November $24^{\text {th }} 2011$, I immediately received a disgruntled email from a Yale alum and self-described "major donor" who sought to shame me for "dragging Yale's name through the mud". The reviews were mixed. Some media outlets opined that it was a waste of an expensive Ivy League education to study nightlife, while other, more curious people considered the course an exciting opportunity for students.

Methodologically, I was aware that the seriousness of the course may come into question, and so I was careful to include key historical and theoretical texts on the syllabus. We read historical texts such as Lewis Erenberg's iconic Steppin Out: New York Nightlife and the Transformation of American Culture, 1890-1930 (1981), which focuses on the shift from a Victorian America to a more liberated, more sexually-free America, as well as the cultural implications of that shift. Other texts included Nightclub City: Politics and Amusement in Manhattan (2007) Bruce Peretti's study of the legal history of nightlife in the $20^{\text {th }}$ century. The implications of Peretti's book in particular are vast, speaking directly to the ways in which the increasing pressures and restrictions on nightlife, such as curfews and cabaret laws, actually force nightlife promoters to be more creative in their nocturnal activities. David Grazian's fascinating ethnography, On the Make: The Hustle of Urban Nightlife (2011), focuses on the way University of Pennsylvania students experience nightlife in Philadelphia as a series of "hustles". When we go out, we hustle to get digits from hot people, we use fake IDs and we dress older than we should to hustle our ways into club environments.

More than one student came to the course questioning the possibility of studying nightlife at all. But by the end of the term, students came to the realization that nightlife is not only an international, multi-billion dollar industry-a billion dollar industry in New York City alone-but that to talk about nightlife and why people pursue it is simultaneously to think through issues of race, class, sexuality, desire, escape and the law, to name a few.

In any number of interviews I gave with curious journalists regarding the seminar, the one question that was repeatedly asked was how one could study nightlife while on the dance floor. We associate nightlife with the pursuit of pleasure, so how is it possible, then, for a scholar to approach the club space without disrupting the vibe? Do I arrive at the club with a note pad, quickly interviewing people during the break beat? Do I break out a recorder and start interviewing people right from the dance floor? In other words, how can you study nightlife without upsetting the natural rhythm of a party?

\section{Nightlife As Social SCULPture}

FROM A METHODOLOGICAL STANDPOINT, I approach nightlife in two ways: nightlife as an aesthetic relational experience and nightlife as a site of curation and creation. Approaching a party as a project of curation and creation expands the ethnographic repertoire with a unique and valuable way of knowing, one that transforms history, theory, and observation into real experience. I take my cue from Dwight Conquergood (1991), whose classic 
essay, "Rethinking Ethnography: Towards A Critical Cultural Politics", suggests that the ethnographic method of participant-observation privileges the body as a unique site of knowing. For Conquergood, "Ethnography is an embodied practice; it is an intensely sensuous way of knowing. The embodied researcher is the instrument" (1991: 180). The problem, however, with a purely participant-observational approach to ethnography is that the published text becomes the key piece of evidence rather than the original experience of the ethnography itself. In this way, when presented in their scientific, highly specialized article format, ethnographies sacrifice the actual experience in favor of theory and critical analysis (1991: 181).

Drawing on the work of Victor Turner, Conquergood concludes that performance offers an ideal remedy to ethnography's shortcomings, in that it can largely reanimate and accompany an ethnographic text. Ethnographic co-performance allows the ethnographer to change roles from a distanced observer to a deeply engaged, intimately involved co-author of the experience (1991: 188). Although ethnography already privileges the body as a site of knowing, the articulation of that knowledge in words is not always effective, particularly since not all experiences and epistemologies are verbal ones (1991: 189). For Conquergood, it is not so much that standard ethnography is insufficient-he is not interested in abolishing the text. Instead, he encourages us to use co-performance to animate and decenter the text. In this way, performance is an alternative, a supplement to text, theory and history (1991: 191).

Conquergood's emphasis on the importance of performance in making ethnography come alive, and my use of his terms for thinking about how to study nightlife cultures, are further animated when thought in relationship to nightlife as an aesthetic experience or "social sculpture". By social sculpture, I mean the trajectory a party takes from a thought or idea to an actual situation that bodies can tangibly experience. This is, in other words, everything that goes into making the party real. To reach that point, a number of things need to happen: hosts, a venue, a DJ, the décor, the dress code, performers and the door person; all of this needs to be decided beforehand. These are the sculptural elements of nightlife because the creative directors in charge of the party work to bring a specific vision to life; and yet, what they cannot anticipate is how exactly an audience will respond. Nightlife is a social sculpture because the agents pulling the party together inject a number of elements and propositions into a dark space, with the goal of keeping a group of people entertained for hours. In my view, a party is always about how bodies have activated and responded to those sculptural propositions.

When we approach nightlife as a social sculpture, when we are directly engaged with the creative experience of actually pulling a party together-throwing disparate elements into the room and waiting to see how people interact with them-we are introduced to a different, relational way of interpreting human behavior. As French art theorist Nicolas Bourriaud describes, a relational aesthetic endorses the view that to stage human encounters is already to stage a work of art (1998: 44). Art itself is a state of encounter, one that demonstrates the features of a particular social world. For Bourriaud, "in order to create a 
world, this encounter must be a lasting one: the elements forming it must be joined together in a form, in other words, there must have been 'a setting of elements on one another (the way ice 'sets')" (1998: 19, my emphasis). Thus, this lasting encounter, or ability to keep audiences interested, becomes a kind of form, a critical proposition. This particular encounter can only be experienced in the dynamic relationship that arises when we are directly confronted with a series of artistic or philosophical propositions (1998:21).

The relational, creative and curatorial possibilities of nightlife are the artistic propositions that are introduced into the night space-the venue itself, the logo, the music played, the kinds of people targeted-and all of this serves not only to brand the party itself but also as a method of communicating to the targeted audience that this party is for them. Sarah Thornton has argued that club cultures are taste cultures, where fantasies of identity are placed on display for public consumption (1996: 3, 91). With much choice in terms of where to go after sunset in large urban centers, clubgoers automatically align themselves with the kinds of clubs and parties that they identify with most, clubs that promise to offer the particular experience they are after, whether that experience is a hook-up with a particular kind of person, a kind of drug, or a specific genre of music. Through the use of flyers and publicity, by the time a clubgoer arrives at the door to a nightclub, they have already done the work of pre-selecting and sorting out the right environments for themselves (1996: 3, 96).

I could not have arrived at the notion of nightlife as a social sculpture without having tied my historical studies of nightlife to my own experience as a party host. In the following section, I focus on Studio 54 as merely one example of the party as social sculpture, an act of curation and creation, a process of curation that began with the infamously tight door to the nightclub. I have selected Studio 54 specifically because of the indisputable role that the notions of "theatricality" and "casting" played in the experience there. I am interested in what happens when we think about nightlife as a production, as a type of theatrical space.

\section{DOOR POLICIES}

THE BRAINCHILD OF New York-bred nightlife entrepreneurs Steve Rubell and Ian Schrager, Studio 54 flung its doors open for the first time on 26 April 1977 and, between its opening and a police raid that occurred on 14 December 1978, barely two years later, Studio 54 would freeze in time to become the most gimmicky night club in New York history. Clubs are frequently measured by their hotness, leading the sociologist David Grazian to describe "hotness" as the way "consumers flock to the nightclubs deemed most fashionable", where they "will suffer long queues and suffocating crowds to luxuriate in the places considered the hot spots of the moment, the epicenters of cool" (2011: 63). My primary interest in Studio 54 has to do with how the club brokered its own hotness. As Jim Fouratt, the manager of the 1980s nightclub Danceteria once said about Studio 54, "looking fabulous was the only thing that got you past the door" (Post 1992: 25).

The fact that Studio 54 was a nightclub in an old television studio is key for thinking 
about how the nightclub connected itself to theatricality. Writing about Le Palace in Paris, an old $17^{\text {th }}$ century theater that was also rehabilitated into a night club in the wake of Studio 54, Roland Barthes describes the club itself as a spectacle of lights, bodies and dancing. Moreover, it is

indeed a place devoted to seeing: you spend your time looking around the room, and, when you come back from dancing, you start looking again...you look at the lights, the shadows, the decor, but you also do something else at the same time (dance, talk, look at each other): a practice known in the ancient theater (Barthes 2010: 120-4).

For Barthes it is no wonder that the spectacle of nightlife occurs in the reclaimed space of an old theater, which merely returns the building to its original intent as a space devoted to different lines of sight and practices of looking.

Though there were already hundreds of discotheques open in New York City at the time, Studio 54 was perhaps the first to deliberately frame nightlife as an extension of the theater-not least because of its proximity to Broadway. In the April 1977 issue of Interview magazine, Carmen D'Alessio, who was hired to promote the new venue, offered readers a preview of a new discotheque set to open at the end of the month:

You walk in under a big marquee. I would say that the opening night will be like going to a premier more than going to a discotheque. Then you walk into this enormous hall with very, very high ceilings and Art Deco mirrors and crystal chandeliers and then into this enormous, enormous room where there are like 85 -foot ceilings-it's like five stories. It's the backstage of a television set with the wires and the cords and you know the place where the cameraman sits? Even that is there, too. The dance floor is 11,000 square feet. It's very, very large. Then upstairs is a theater with a seating arrangement (Colacello 1977: 42).

In her preview, D'Alessio describes how the nightclub will offer a unique, curated experience. But most important is her characterization of the club's architecture as the backstage of a television studio. This is telling, because Studio 54 emerged as media saturation and celebrity culture reached a peak. In 1969, Andy Warhol launched Interview, a magazine of unedited interviews with celebrities. According to Warhol, at that time "everyone, absolutely everyone, was tape-recording everyone else. Machinery had already taken over people's sex lives - dildos and all kinds of vibrators - and now it was taking over their social lives, too, with tape recorders and Polaroids" (2006: 367). Realizing the possibilities for this new fad, Warhol discovered that tapes introduced new possibilities for interviews with celebrities:

Since we were a long time between movies lately, I began to think about starting a magazine of nothing but taped interviews. Then John Wilcock dropped by one day and asked me if I would start a newspaper with him. Together we brought out the first issue of Interview magazine in the fall of '69 (Warhol 2006: 367-8). 
Perhaps more famous than the club itself are the well-publicized stories about who could not get into this tightly curated space. Supposedly John Kennedy, Jr. and Warren Beatty at one point did not get in (Los Angeles Times 1989: 26). Andy Warhol remembers being nervous about not getting in every time he went, despite being a regular guest (Warhol 1980: 50). Studio's dictator-like door policy was so infamous that even taxi drivers, those overlooked yet key figures in nightlife, played the role of doorman. One driver confessed: "I tell people not to go there because I know they're not going to get in. I know which ones will get in. I try to tell them they just aren't dressed right" (Capote et al 1979: 33).

What in particular did the experience of Studio 54 offer its patrons? Moreover, if Studio managed to craft and popularize an image of exclusivity and denial wherein patrons knew that admission could be next to impossible to achieve, why did they continue to show up every night? What is the power of the nightclub door?

Sometimes the most difficult aspect of going out is getting in, even when one is on the guest list. What interests me about exclusive nightlife settings and door culture is not that a space has an exclusive door policy, but that there is a market for spaces with exclusive door policies to begin with. In my experience, I have found that the more difficult it is to gain access to a place, the more fabulous it seems and thus the more desirable access to the venue becomes. In 1931, the actor Jimmy Durante described the door scene of an all-black revue starring the cabaret singer Florence Mills that used the impossible door to stir public interest. The show was conceptualized by Broadway producer Lew Leslie, who had the novel idea to create a publicity stunt to attract an even larger audience to see Mills perform, who was already a headlining talent in New York and Paris. When excited fans approached the door of the Plantation Club, they could hear live music pouring out onto the sidewalk. But imposing, red velvet curtains were drawn over the club door, and a sizable bouncer stood on the outside explaining that he could not let anyone in. Inevitably, the concertgoers would ask if they could come back tomorrow, and the bouncer told them that the reservation list was full then, too. This was despite the fact that there was no reservation list and that no one was actually on the inside of the club. This performance of rejection went on for weeks, after which the doorman started to let people in, and the show became a runaway success (Durante 1931: 176). As Durante observed, there is a certain "New York manner of flocking only to places where it's hard to get in" (1931: 176). Aside from illustrating a history of door policy, what emerges from this particular example is the fact that crowds attract crowds, and the more crowded a place appears, the more in-demand it becomes.

Rejection from the door of Studio 54 reveals important theories about how the club's own image and reputation was solidified: through the myth of the tight door. A tight door policy means that simply waiting in line and paying the fee to enter a club does not guarantee admittance. Instead, bodies are read and subjected to intense scrutiny by a door person, who selects the "right" people to let in from a crowd of many. Door cultures are thus image cultures as well as taste cultures that are managed by rites of self-selection, curation, and mixing that reinforce and establish belonging among disparate groups. This mixture of sexualities, styles of dress, backgrounds, class and levels of fame enforced by the tight door- 
what Rubell often referred to as "making a salad"-was central to Studio 54's popularity. As clubgoers approached the door as a stylized, heightened version of themselves, doormen curated the right people from the crowd as a way to produce a site of belonging where bodies from diverse backgrounds could intersect intimately in a way that might not be possible outside of the club context (Malbon 1999: 51). A tight door policy thus creates a site of curated bodies, where the curation relates to the specificity of what a given person will contribute to the party in order to sustain its energy.

In archival footage of the door scene at Studio filmed in 1979, hundreds of well-dressed people on narrow 54th Street are herded behind a plush velvet rope, their arms held high in the air. Their arms are held high because they are working to get the attention of Marc Benecke, the doorman at Studio 54 and the last word on who may enter the space. Commenting on how he selects people to enter, Benecke said that he:

would just zero in on somebody I knew was going to get in and frankly pretty much ignore people who I knew weren't going to get in. And the funny thing was when I did change tactics and say to people, 'I'm really sorry. You really don't have a chance. Maybe you should come back another night' they would just stand there for two or three hours anyway. It was amazing to me that anyone would do that. But there was such a fervor. Such a need to be inside (Haden-Guest 1997: 56-62).

Benecke is perched atop a red standpipe, peering over the crowd, combing through it with his eyes, pointing and waving forward those he wants to admit. As the audience fights for Benecke's attention, what becomes clear is that this door scene reveals in-the-middle-ofsomething-ness or the excitement around the-about-to-transpire. There are thus two scenes at Studio 54-the activity on the inside of the club that is driven by heightened sensory experiences that drugs, music and dancing facilitate, and then there is the spectacle of street theater on the outside of the club where audiences wait in anticipation.

In my reading, the door scene at Studio functions as a site of intensified energy. By intensified energy, I mean that the aura of the space proposes potentiality and possibility. The audience realizes that it is on the cusp. This is what Village Voice columnist Michael Musto meant when he remembered that "we would just stand outside [of Studio 54] for hours and hours, and that would be a full night's entertainment, just watching the celebrities' limousines pull up, and see who would come out of them. We didn't even try to get in"(Haden-Guest 1997: 59). For Musto, staying out amid the hype was where the critical event took place because the door scene was an event that fueled anticipation.

Studio 54 did not invent the tight door nor the velvet rope. Nonetheless, Studio's strenuous door policy marks the beginning of the popularization as well as the mainstreaming of "door culture" in New York nightlife. On 31 August 1979, the New York Times published a story entitled, "The Last Word at Discos Belongs to the Doormen", an in-depth article about the impact of door culture at the leading nightclubs in the city. Despite what their job title suggests, the article opined, doormen "aren't around to open and close doors; they're around to decide whether the door is going to open at all for you, and you, and you" (Nemy 
1979).

Scholars of club cultures have theorized the door to these types of in-demand spaces as sites of control, exclusion and racism. As Paul Chatterton and Robert Hollands argue in a study on the political economy of urban nightlife, door cultures are used as a systematic "mechanism for distinction and exclusion" (2003: 59). Importantly, these distinctions are class-based but they are also often rooted in subcultural capital and the legibility of hipness (Thornton 1996: 11). Each nightclub has its own set of discriminatory tools listed under the blanket of "entry requirements" as a way to facilitate entry or denial. In one field experience, I observed the door to a Midtown Manhattan nightclub and watched a young black man get thrown out of the line because he was wearing tennis shoes and baggy jeans. Fashion and self-styling play a key role in impression-management and the legibility of bodies in socio-theatrical situations. What impression, exactly, did the combination of the man's blackness, his tennis shoes and his baggy jeans communicate to the door person? The fear of certain kinds of styles raises important questions about the dialogue between fashion and the discriminatory social structures built into the club experience.

In Ben Malbon's words, "bouncers on 'the door' at clubs can also reinforce wider societal prejudices in respect of ethnicity, gender and 'good looks"'(1999: 64). At the height of Studio 54's popularity, the increasing use of the tight door to promote exclusivity based on appearance led the head of the New York State Liquor Authority to caution club owners that their admission policies might infringe on individual constitutional rights. Any rule "barring admission is a violation of Rule 36 (d) of the rules of the State Liquor Authority, and could result in license revocation proceedings" (Roth 1977). One New York restaurateur sued the exclusive nightspot Régine's for $\$ 2$ million dollars in damages because he and his wife were barred entry (Roth 1977). Unless these stiff policies were relaxed, the commissioner warned that a club could be shut down.

But it must also be noted that nightclub doors are sites of curation. In a profile of doormen that appeared in the New York Times in 1979, Charles Yancy, the door person at the Xenon, a popular Off-Broadway club that emerged after Studio 54, remarked that every night he would "Look around and see what I created-every night it's different" (Nemy 1979). Here, curating an audience for the party has to do with the art of the mixture-that is, of insuring that people from a diversity of backgrounds are represented. Shane Vogel has shown how "intimacy" facilitates the art of the mixture by creating unique, intimate situations, or what I would call "social sculptures", wherein disparate groups suddenly find themselves in a shared space with a unique set of commonalities linked to various subcultural tastes in fashion, music, or styles of dance. And, as Sarah Thornton describes, club cultures create- or curate-the right social sculpture by relying on tools of targeted promotion that include flyers, telecommunications, promoters and finally door policy, which she sees as the last resort to insure that the club has targeted the right audience. For Thornton, the club audience is already pre-selected and pre-sorted, and door policy becomes a final measure to segregate the crowd from those who "belong" or fit the mix from those who do not (1996: $23-4)$. 
And yet, the process of curating bodies is also the process of casting. As one door person remarked in 1979, "I feel like I'm casting a show every night" (Nemy 1979). If a tight door relates to the theatrical act of casting, then the logic behind Studio 54's tight door policy becomes especially clear. I have already shown how 54 built its image around the bald use of the media, paparazzi culture and the television studio, where the raised stage was the dance floor and where those admitted walked through a mirrored lobby with old CBS boom mics and television cameras still in place.

The near-impenetrable door was therefore the curating of a group, but it was also very literally the filmic, televisual and theatrical casting of actors for the play of nightlife. As Warhol remembered, "the key to the success of Studio 54 is that it's a dictatorship at the door and a democracy on the floor. It's hard to get in, but once you're in you could end up dancing with Liza Minnelli. At 54, the stars are nobody because everybody is a star. It's the place where my prediction from the sixties finally came true: 'In the future everyone will be famous for fifteen minutes'" (1979: 48). The nightly act of casting, in the language of star-making, linked Studio 54 to performance and celebrity culture. Studio's immense popularity was borne out of the way it brought the excitement of celebrity culture-typically experienced via a screen - to the masses and gave audiences a chance to participate in the spectacle. In the process, the club signaled key changes in American culture, media and the experience of celebrity.

\section{Conclusion, or Why the Party is Research}

IN MY OWN EXPERIENCE as a clubgoer, I have always been drawn to the kinds of glamorous, excessive parties where straight people, gay people and anybody in between inhabit the same space. In 2009 I was visiting a collection of fashion archives at UCLA and found myself spending time in Echo Park in my downtime. I wandered into the Echo Park Independent Co-op, a fashion boutique that only carries clothes by local designers, and I told the boutique owner that I came to L.A. in search of fabulousness. Her face instantly lit up. "You have to go to RHONDA", she told me. When I asked what RHONDA was, she said that it was the stomping ground for L.A club kids, that it was "a fashion party. Very Studio 54. Gay, straight, anything goes". I was so excited. When I got to RHONDA, which was held at the El Cid restaurant that night, the queue stretched down the block. The party was full of people from varying ethnic backgrounds and sexualities, some dressed casually, others working serious looks. The door person was a drag queen, but it was not a gay party. In other words, the nightlife I find the most exciting is where it exists in a space of convergence, where people from a variety of backgrounds come together.

Going out is an occasion, an event, a special part of the week where we are free to fully express ourselves. If I am planning to spend hours in a club, I want to be excited and inspired by other people's creativity. I want to have exchanges with people based on their creative output. This is not to say that every party needs to be a dress-up party, that non-dressup parties are no fun or that people who don't dress up are doing it all wrong. Nightlife 
cultures are taste cultures, and my particular taste is for being in a space with different kinds of people who have a range of approaches to and expressions of their bodies. But even as I critique this more monochromatic form of nightlife, I should point out that people usually have a number of reasons for going out-for sex partners, for music, to be seen and to make friends, and each of these reasons has its own dedicated nightlife scene.

Curating a party is like tossing a salad, as Steve Rubell put it. And one of the things I have learned as a host is that a party loses its steam when the crowd is too monolithic. No matter how much I prefer transgressive dress up parties, every attendee does not need to be in a look because too much sameness actually makes things boring and destroys the element of surprise.

When I hosted the party with Amanda Lepore at Santos Party House in New York, part of the goal was to use hosts to attract diverse audiences. Party hosts are like brand names, and when a particular name is splashed on the face of a flyer or attached to the party in some way, that alone says a great deal about what kind of party it is going to be. Every party host is plugged into a different set of subcultural universes. This particular party listed Andrew WK as the "Master of Ceremonies", but it also listed performances by Cherie Lily, Amanda Lepore and Cazwell, three icons within the New York gay scene. Moreover, it indicated that Vjuan Allure would be spinning, and he is one of the biggest DJ names in the house/ ballroom circuit. In curating the names on the flyer for our party, we essentially sent signals to a number of subcultures at once. Those who like Andrew WK will come out to see him, but those who want to vogue will come because of Vjuan Allure. Whoever is hosting a party or whatever performances are scheduled has a great deal to do with the kind of audience that eventually shows up.

In my role as a nightlife host and creator of parties I have learned three key things about the culture of the night that have been instrumental in my research. First of all, scholars and ethnographers of nightlife can learn a great deal from the "tossing a salad" metaphor. We must talk to the party hosts and party promoters themselves, who are responsible for putting the "salad" together. We need to talk to them about their jobs, what they do, and how they approach a particular party. Even though scholars of nightlife can learn a great deal by talking to the clubgoers themselves, it is the promoters who have created the sculptural elements and artistic propositions that clubgoers experience. Ask them how they chose a particular venue and why. Inquire about how they decided which performers to book or about how they design the flyers, where they put them, and how they are advertised. Some promoters in large urban centers place flyers in record shops, cafes or boutiques, but others create more of a mystique by sending email blasts, text messages from disposable numbers or by building an aura of secrecy around the event by requiring a password to get in.

Aside from thinking through how the salad of nightlife is tossed together, or how the social sculpture is formalized, scholars and ethnographers of night cultures should explore how their work is animated when they approach a party as a theatrical production. In many ways, the promoter acts like a director who casts all the elements and brings a party to life. By thinking about a party as a theatrical production we are then forced to think thorough 
all of the technical issues involved in assembling an audience: the use of space, lighting, decoration and design, the kind of music played, whether people are dancing and how they are interacting with the space overall. But we should also consider how the audience interacts with the sculptural elements and relational propositions that have been placed before them.

The final piece of the puzzle for any ethnographer studying nightlife as a cultural form is to assess one's own relationship to the night world that one is studying. This entails an honest and blunt assessment of one's own subcultural privilege and the potential impact of one's study on this social world. My dissertation advisor once asked me whether or not I had any advantage in my work on exclusive spaces such as velvet-rope nightclubs and luxury boutiques because of the way I present myself. Honestly, I had never thought about it that way before, but it is true that I do read in specific ways to given subcultures, and taking account for how we are either afforded or denied access based on how we read is a fascinating aspect of any ethnography.

I have tried to connect the lines between nightlife as a social sculpture and nightlife as a process of casting and curation. As much as we can learn theories about space or read histories of night cultures, being responsible for your own parties adds new layers of understanding about how night worlds come together and what they mean. When we create our own parties or events, we stop thinking like scholars, at least temporarily, and begin thinking like innovators and creators with an aesthetic goal in mind. We realize that a party never simply happens, but rather that much creative work has gone into putting it together.

\section{ACKNOWLEDGEMENTS}

Thanks to Simonez Wolf and Cody Allen for showing me the way. I would also like to thank Cherie Lily, Andrew WK, Leo Gugu, Aleksey Kernes, Steve Lewis, Chris Alker, Gregory Alexander, Kayvon Zand and Gamal Hennesey. And thanks to New York nightlife icon Susanne Bartsch for being fabulous.

\section{REFERENCES}

Boorstin, Daniel. 1980. The Image: A Guide to Pseudo Events in America. New York: Atheneum. Bourriaud, Nicolas. 1998. Relational Aesthetics. Paris: Les presses du réel.

Buckland, Fiona. 2002. Impossible Dance: Improvised Social Dance as Queer World-Making. Middletown, CT: Wesleyan University Press.

Capote, Truman Andy Warhol and Bob Colacello. 1979. "Steve Rubell: In the Heat of the Night". Interview, February: 30-36.

Chatterton, Paul and Robert Hollands. 2003. Urban Nightscapes: Youth Cultures, Pleasure Spaces and Corporate Power. New York: Routledge.

Colacello, Bob. 1977. "Oh Carmen!" Interview, April: 42. 
Conquergood, Dwight. 1991. "Rethinking Ethnography: Towards a Critical Cultural Politics". Communication Monographs 59: 179-94.

Dyer, Richard. 1979. "In Defense of Disco". Gay Left, Summer: 20-23.

Erenberg, Lewis. 1981. Steppin' Out: New York Nightlife and the Transformation of American Culture, 1890-1930. Chicago: University of Chicago Press.

Fikentscher, Kai. 2000. "You Better Work!": Underground Dance Music in New York City. Hanover, $\mathrm{NH}$ : University Press of New England.

Grazian, David. 2011. On the Make: The Hustle of Urban Nightlife. Chicago: University of Chicago Press.

Haden-Guest, Anthony. 1997. The Last Party: Studio 54, Disco, and the Culture of the Night. New York: William Morrow.

Lawrence, Tim. 2003. Love Saves the Day: A History of American Dance Music Culture, 1970-1979. Durham: Duke University Press.

Los Angeles Times. 1989. “Steve Rubell Obituary”. 27 July.

Malbon, Ben. 1999. Clubbing: Dancing, Ecstasy and Vitality. London: Routledge.

Nemy, Enid. 1979. “The Last Word at Discos Belongs to the Doormen”. New York Times, 31 August: A14.

Peretti, Bruce. 2007. Nightclub City: Politics and Amusement in Manhattan. Philadelphia: University of Pennsylvania Press.

Post, Henry. 1982. "Heart of Darkness". New York, 3 May: 24-30.

Roth, Robert. 1977. "NY Club Scrutiny Draws Liquor Board Fire”. Billboard, 17 December: 68.

Thornton, Sarah. 1996. Club Cultures: Music, Media, and Subcultural Capital. Hanover: University Press of New England.

Vogel, Shane. 2009. The Scene of Harlem Cabaret: Race, Sexuality, Performance. Chicago: University of Chicago Press.

Warhol, Andy and Bob Colacello. 1979. Andy Warhol's Exposures. New York: Grosset \& Dunlap.

Warhol, Andy and Pat Hackett. 1986. The Andy Warhol Diaries. New York: Grand Central Publishing. Kindle Edition. 